\title{
An experimental investigation of HA/AL2O3 nanoparticles on mechanical properties of restoration materials
}

\author{
Majid Safarabadi $^{\mathrm{a}^{*}}$, Nabi Mehri Khansari ${ }^{\mathrm{b}}$ and Abbas Rezaei
}

${ }^{a}$ School of Mechanical Engineering, College of Engineering, University of Tehran, Tehran, Iran

${ }^{b}$ Department of Aerospace Engineering, Faculty of New Sciences and Technologies, University of Tehran, Tehran, Iran ${ }^{c}$ Department of Mechanical Engineering, University of Maragheh, Tabriz, Iran

\begin{tabular}{|c|c|}
\hline $\begin{array}{l}\text { A R T I C L E I N F O } \\
\end{array}$ & AB S T RACT \\
\hline $\begin{array}{l}\text { Article history: } \\
\text { Received January 20, } 2014 \\
\text { Received in Revised form } \\
\text { April, 10, } 2014 \\
\text { Accepted } 27 \text { April } 2014 \\
\text { Available online } \\
29 \text { April } 2014 \\
\text { Keywords: } \\
\text { Polymethyl methacrylate } \\
\text { Hydroxyapatite } \\
\text { Aluminum oxide } \\
\text { Mechanical properties } \\
\text { Hybrid Nano-composite }\end{array}$ & $\begin{array}{l}\text { Nano composite materials based on polymers are widely used in restoration martials like dental. } \\
\text { Poly methyl methacrylate (PMMA) is one of the most used polymers as dental material. } \\
\text { PMMA has disadvantages such as low flexural strength properties and impact strength. In this } \\
\text { paper, the influences of additive aluminum oxide and hydroxyapatite nanoparticles on the } \\
\text { mechanical and strength properties of PMMA (including flexural strength, impact strength, } \\
\text { surface hardness and shrinkage behavior) is studied experimentally. For this purpose, nine } \\
\text { standard mechanical testing samples of pure PMMA, PMMA/5HA and PMMA/10HA with } \\
\text { various amounts of Nano aluminum oxide (3,6,8 wt.\%) were prepared. The results showed that } \\
\text { the mechanical properties of hybrid Nano-composites were significantly improved in } \\
\text { comparison with the pure samples in a way that optimal Nano-composite with convenience } \\
\text { flexural properties and impact strength is obtained. Moreover, the use of nanoparticles results in } \\
\text { shrinkage reduction of hybrid Nano-composites in comparison with pure PMMA. }\end{array}$ \\
\hline
\end{tabular}

\section{Introduction}

One of the most widely used materials in prosthetic dentistry is poly methyl methacrylate (PMMA). Since its introduction to dentistry, it has been successfully used for denture bases because of its ease of processing, low cost, light weight, and color-matching ability. However, acrylic resin denture base materials have poor strength, including low impact strength and low fatigue resistance (Gutteridge,1988; Dabbar \& Huggett, 1994; Lambrecht \& Kydd, 1962; Hargreaves, 1969; Jagger et al., 1999; Kim \& Watts, 2004). A study by Johnston and colleagues (Johnston et al., 1981) showed that $68 \%$ of acrylic resin dentures break within a few years after fabrication. Flexural fatigue occurs 
after separate flexing of a material, whereas impact fracture occurs when extra ordinary forces are applied suddenly (Nally et al., 2006).

Many attempts have been made to enhance the strength of acrylic denture bases including the addition of metal wires and cast metal plates (Vallittu \& Lassila, 1992; Vallittu, 1993; Carroll \& Fraunhofer, 1984; Ruffino, 1985). The primary problem with using metal wire is poor adhesion between the wire and resin, which leads to insignificant enhancement of mechanical properties. Although metal plates increase the strength, they may be expensive and prone to corrosion (Carroll \& Fraunhofer, 1984; Ruffino, 1985; Vallittu \& Lassila, 1992; Vallittu, 1993). Modifications of the chemical structure, by adding crosslinking agents or copolymerization with rubber, result in significant increases in the impact strength. However, stiffness, fatigue resistance, and transverse strength are reduced (Robinson, 1993; Matsukawa et al., 1994; Stafford et al., 1980). Mechanical reinforcement of acrylics has also been attempted through the inclusion of fibers and metal inserts (Gutteridge, 1988; Dabbar \& Huggett 1994; Lambrecht \& Kydd, 1962; Hargreaves, 1969; Jagger et al., 1999; Kim \& Watts, 2004; Uzun et al., 1999; Chen et al., 2001; Sehajpal \& Sood, 1989).

Although the inclusion of fibers produced encouraging results, this method has various problems including tissue irritation, increased production time, difficulties in handling, the need for precise orientation, and placement or bonding of the fibers within the resin (Zarb et al., 2004). In the case of metal inserts, failure due to stress concentration around the embedded inserts has been reported (Jagger et al., 1999; Sehajpal \& Sood, 1989; Ellakwa et al., 2008).

The incorporation of ceramic particles in various dental materials has been studied and found to be biocompatible, and it also improves mechanical properties (Ellakwa et al., 2008; Furman et al., 2000; Zuccari et al., 1997; Ichikawa et al., 1992; Ayad et al., 2008; Panyayong et al., 2002; Saad-Eldeen et al., 2007; Tinschert et al., 2001; Abdel-Samad \& EL-Fallal, 2009). In addition, the white color of the ceramic powder is not expected to compromise aesthetic appearances (Ellakwa et al., 2008; Ichikawa et al., 1992; Minamizato, 1990; Callister, 1997). However, reinforcement methods should not have adverse effects on the mechanical properties of denture materials. The roughness of acrylic resin surfaces is a critical property because surface irregularities increase the likelihood of microorganisms remaining on the denture surface after the prosthesis is cleaned (Radford et al., 1998; Verran \& Maryan, 1997). Another property that can influence the surface characteristics of acrylic resins is the hardness, which indicates the ease of finishing a material and its resistance to in-service scratching during cleaning procedures (Powers and Sakaguchi, 2006).

Although it has been reported that untreated aluminum oxide $\left(\mathrm{Al}_{2} \mathrm{O}_{3}\right)$ powder develops physical properties of high impact acrylic resin, (Ellakwa et al., 2008) there have been no investigations regarding the effect of $\mathrm{Al}_{2} \mathrm{O}_{3}$ Nano- powder and Nano hydroxyl apatite (Nano- HA) on the mechanical properties of a conventional cold-cured acrylic resin. Therefore, we investigated the effects of $\mathrm{Al}_{2} \mathrm{O}_{3}$ at three different concentrations (3, 6, 8 \%wt) with two concentrations of $\mathrm{HA}(5,10$ \%wt) on the flexural strength (FS), impact strength, surface hardness and shrinkage behavior of a conventional cold-cured acrylic resin. The hypothesis was that adding $\mathrm{Al}_{2} \mathrm{O}_{3}$ and $\mathrm{HA}$ would increase the flexural strength, impact strength and hardness compared to the control group (unreinforced acrylic resin specimens).

\section{Materials and methods}

\subsection{Materials}

In this study, self-curing acrylic resin (cold-cured acrylic resin) as polymers and nanoparticles of hydroxyapatite and alpha-alumina as reinforcing factors (reinforcement) has been used. Properties of these materials are given in Table 1. 
Table 1. Properties of materials used in this research

\begin{tabular}{|c|c|c|}
\hline Material & Characteristic & Producer \\
\hline $\begin{array}{l}\text { Poly methyl } \\
\text { methacrylate }\end{array}$ & $\begin{array}{l}\text { Powder: methyl methacrylate } \\
\text { Liquid: methyl methacrylate monomer, catalyst }\end{array}$ & $\begin{array}{l}\text { Product trade name Acropars } \\
\text { Medical Industries Malik, Iran }\end{array}$ \\
\hline $\begin{array}{l}\text { hydroxyapatite } \\
\text { nanoparticles }\end{array}$ & $98 \%$ purity and average size of $30 \mathrm{~nm}$ & Products, Merck, Germany \\
\hline $\begin{array}{l}\text { nanoparticle- } \\
\text { alumina }\end{array}$ & Alpha type, 99.7 purity\%, , and the average size of $80 \mathrm{~nm}$ & Products, China \\
\hline
\end{tabular}

\subsection{Sample Preparation}

First of all raw materials, including monomer methyl methacrylate, nanoparticle-alumina and hydroxyapatite nanoparticles powders, heated at $90^{\circ} \mathrm{C}$ in a furnace under vacuum condition were dried for one hour. In order to prepare the samples and to obtain uniform distribution of hydroxyapatite and alumina nanoparticles in the polymer and also reduce the amount of aggregation, grinding technics has been used. In this way the device is used under vacuum mixer (Whip Mixmodel F, USA). Methylmethacrylatepowder, hydroxyapatite nanoparticles with values of 5 and 10 $w t \%$ and 10 wt\% alumina particles with values of 6.3, was placed in the mixer. Milling was performed for $10 \mathrm{~min}$ with $20 \mathrm{~Hz}$ frequency. After mixing, preparation of all samples for liquid and solid components at portion of 5 to 5.3 was used. Mixed powders of methyl methacrylate, Nanohydroxyapatite and Nano-alumina as a solid and monomermethyl methacrylate and catalyst were considered as a liquid fraction. To produce Nano composite samples, these two parts were mixed mechanically according to the manufacturer's instructions, at ambient temperature. After reaching the dough stage, and after about 2 to 5 minutes (depending on the model), the paste was put into the mold using a pressure molding (Fig.1).

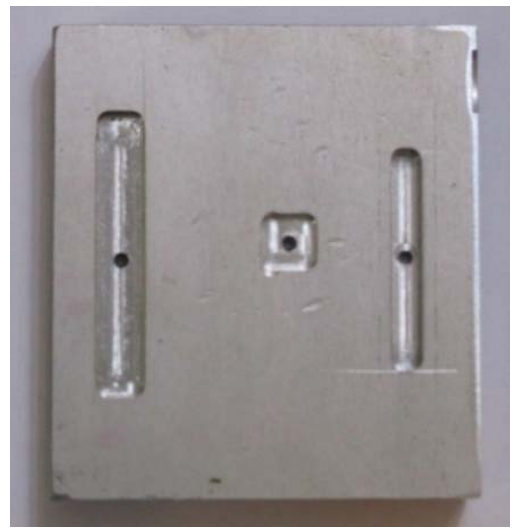

Fig. 1. Pressure molding manufactured and employed in this research

After 15 to 20 minutes the paste became hard, and the samples were removed from the molding. Weight percentage of prepared mixed materials (wt.\%) are listed in Table 2.

Table 2.Weight percentage of nanoparticles in Nano composites

\begin{tabular}{|c|c|c|c|c|}
\hline No. & Blended components & hydroxyapatite nanoparticles & $\begin{array}{l}\text { Nt.\% of components } \\
\text { nanoparticle-alumina }\end{array}$ & Polymethyl methacrylate \\
\hline 1 & PMMA & 0 & 0 & 100 \\
\hline 2 & PMMA/5HA & 5 & 0 & 95 \\
\hline 3 & PMMA/10HA & 10 & 0 & 90 \\
\hline 4 & $\mathrm{PMMA} / 5 \mathrm{HA} / 3 \mathrm{Al}_{2} \mathrm{O}_{3}$ & 5 & 3 & 92 \\
\hline 5 & $\mathrm{PMMA} / 5 \mathrm{HA} / 6 \mathrm{Al}_{2} \mathrm{O}_{3}$ & 5 & 6 & 89 \\
\hline 6 & PMMA/5HA/8Al ${ }_{2} \mathrm{O}_{3}$ & 5 & 8 & 87 \\
\hline 7 & $\mathrm{PMMA} / 10 \mathrm{HA} / 3 \mathrm{Al}_{2} \mathrm{O}_{3}$ & 10 & 3 & 87 \\
\hline 8 & $\mathrm{PMMA} / 10 \mathrm{HA} / 6 \mathrm{Al}_{2} \mathrm{O}_{3}$ & 10 & 6 & 84 \\
\hline 9 & $\mathrm{PMMA} / 10 \mathrm{HA} / 8 \mathrm{Al}_{2} \mathrm{O}_{3}$ & 10 & 8 & 82 \\
\hline
\end{tabular}




\subsection{Tests}

Properties of the Nano composites, were investigated using three-point bending mechanical tests, impact IZOD tests and hardness tests. Using the molds shown in Fig. 1, three types of samples were manufactured. Fig. 2 shows the standard samples that are produced in this research. Bending test specimens with dimensions of $65 \mathrm{~mm} \times 10 \mathrm{~mm} \times 3 \mathrm{~mm}$ were produced in aluminum mold. Threepoint bending tests with bottom loading span of $50 \mathrm{~mm}$ as shown in Fig. 3 were carried out with the rate of $5 \mathrm{~mm} / \mathrm{min}$. The bend tests were performed using ZWICK Z250 test machine (ZwickRoell Group, Herefordshire,UK) Un-notched impact test specimens with dimensions of $50 \mathrm{~mm} \times 6 \mathrm{~mm} \times 4$ $\mathrm{mm}$ were produced in aluminum mold. The test device (SANTAM-SIT20D, Iran) with adjust of $0.5 \mathrm{~J}$ energy was performed. Vickers hardness test specimens having dimensions of $12 \mathrm{~mm} \times 12 \mathrm{~mm} \times$ $3 \mathrm{~mm}$ were also produced in the aluminum mold. Vickers hardness test using (Otto Wolpert, Werke, Ludwigshafen, Germany) and 30g load was done in duration of 30s. The whole mechanical properties tests were performed at room temperature, and each test was repeated three times. In order to avoid form shrinkage, standard bending test specimens were used. Dimensions of the mold cavity were considered as the reference measure and by measuring the length of the samples and comparing them with the reference measurement, the rate of shrinkage was calculated. The shrinkage measurement tests were repeated 3 times for each blend.

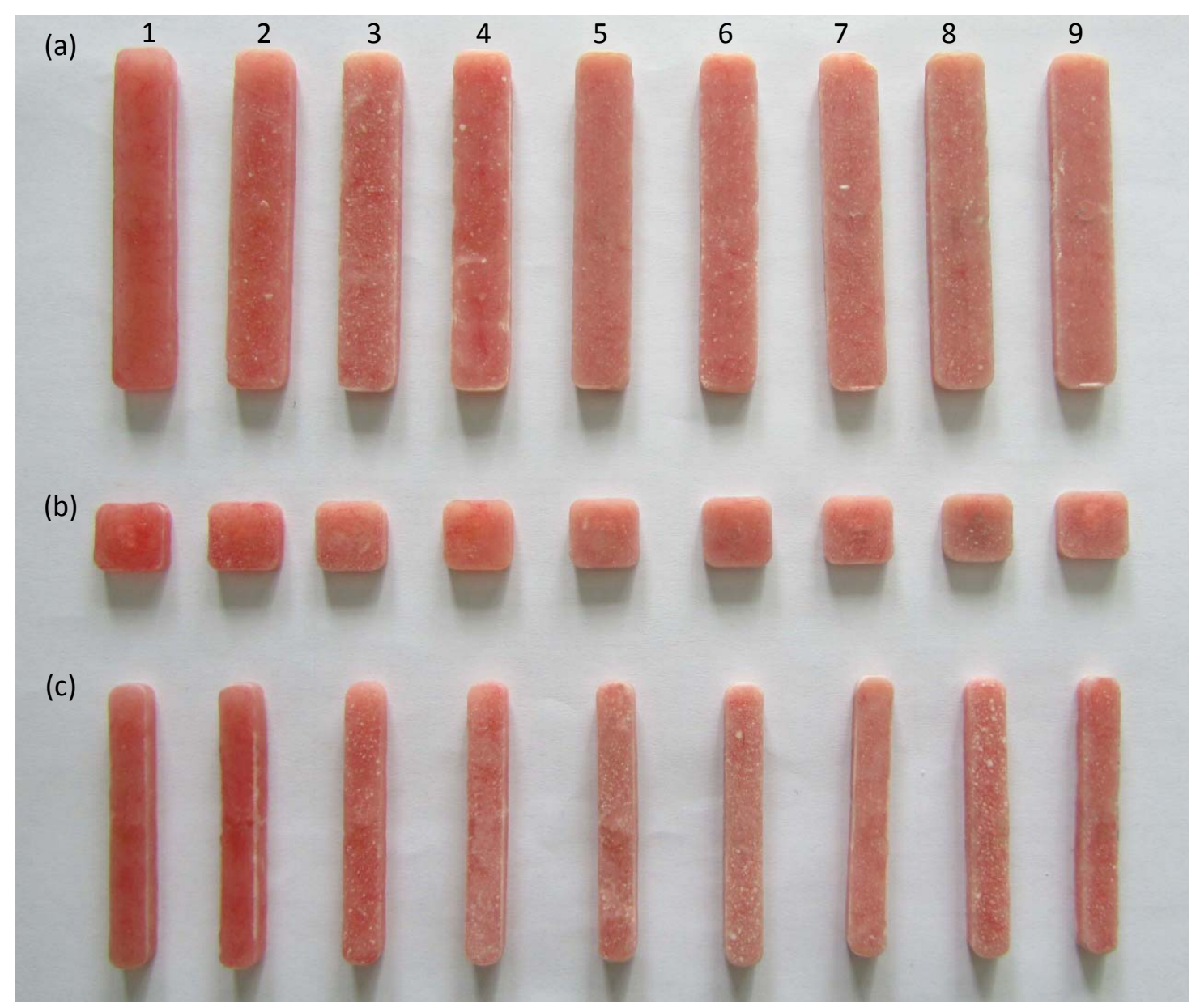

Fig. 2. Standard test samples a) flexural test, b) hardness and c) impact test 


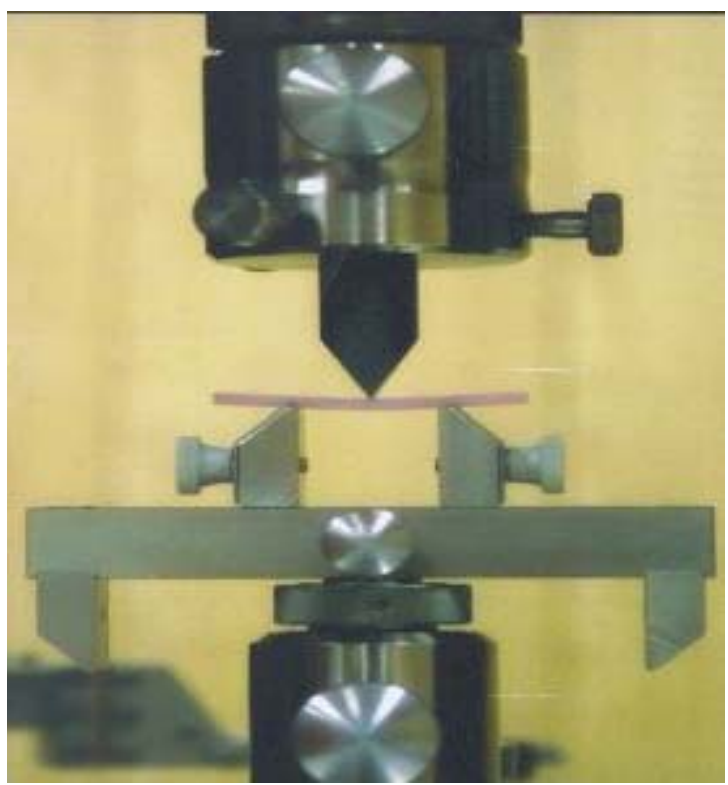

Fig. 3. Three-point bend test set up

\section{Results and Discussion}

Fig. 4 indicates the effect of adding the Nano-hydroxyapatite and Nano-alumina on the flexural strength of the blends. As seen from this figure, by adding the weight percentage of hydroxyapatite and alumina, flexural strength was increased. Hybrid Nano-composites with 5 and $10 \%$ wt. of HA and $6 \%$ wt. of $\mathrm{Al}_{2} \mathrm{O}_{3}$ have the maximum flexural strength. The flexural strength of these blends is respectively $30 \%$ and $35 \%$ greater than the neat PMMA. High strength Nano-alumina and hydroxyapatite bio ceramic as a stiff phase to polymer matrix has a positive effect, lead to increase the flexural strength. At high percent of both nanoparticles, flexural strength was decreased. These findings are consistent with the Shibata et al. (2007) and also Sodagar et al., (2012) on addition of silver nanoparticles to acrylic resin and can be attributed to the effect of Nano-sized oxides on the internal structure of polymerized PMMA. In addition, $\mathrm{Al}_{2} \mathrm{O}_{3}$ exists in several crystalline phases, and all filler particles revert to the most stable hexagonal alpha phase at elevated temperatures. This is the phase of particular interest for structural applications (Grant and Greener, 1967). When sufficient stress develops and micro cracks start to propagate, the transformation phenomenon occurs, which depletes energy for crack propagation (Ayad et al., 2008). Therefore, proper distribution of the filler within the matrix can stop or deflect the cracks.

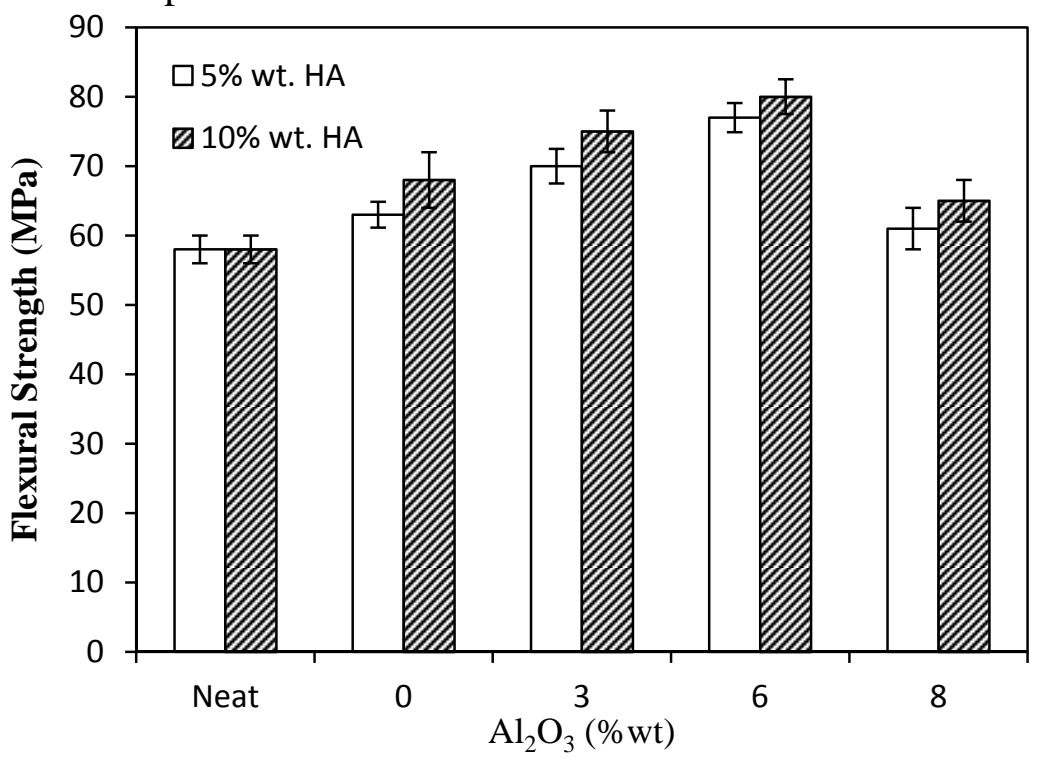

Fig. 4. The effect of adding hydroxyapatite and aluminaon the flexural strength of blends 
The addition of $8 \mathrm{wt} \% \mathrm{Al}_{2} \mathrm{O}_{3}$ Nano-powder in the blends with 5 and $10 \%$ wt. HA caused a decrease in flexural strength compared to other Nano-composites. Possible explanations for this reduction in the strength could be: a decrease in the cross-section of the load-bearing polymer matrix; stress concentration because of too many filler particles; changes in the modulus of elasticity of the resin and mode of crack propagation through the specimen due to an increased amount of fillers; void formation from entrapped air and moisture; incomplete wetting of the fillers by the resin; and the fact that $\mathrm{HA}$ and $\mathrm{Al}_{2} \mathrm{O}_{3}$ nanoparticles acts as an interfering factor in the integrity of the polymer matrix.

According to Fig. 5, the impact strength of blends was increased with increasing of the nanoparticles weight percent. The only HA has insignificantly effect on the impact strength, but inclusion of $\mathrm{Al}_{2} \mathrm{O}_{3}$ nanoparticles lead to increase of impact strength significantly. Hybrid Nano-composite with 10 \%wt. HA and $6 \%$ wt. $\mathrm{Al}_{2} \mathrm{O}_{3}$ has the highest impact strength compared with the other blends. The impact strength of this hybrid Nano-composite is approximately 2.5 times greater than that of neat PMMA. The increase in the impact strength at $6 \% \mathrm{wt}$. of $\mathrm{Al}_{2} \mathrm{O}_{3}$ nanoparticles due to the interfacial shear strength between Nano filler and matrix is high due to formation of cross-links or supra molecular bonding which cover or shield the Nano fillers which in turn prevent propagation of cracks. Also the crack propagation can be changed by good bonding between Nano filler and resin matrix (Sun et al., 2009). In addition, void formation around nanoparticles led to increase of impact strength. Decrease of impact strength at high percentage of nanoparticles (10\%wt. HA and $8 \% w t$. $\mathrm{Al}_{2} \mathrm{O}_{3}$ ) was attributed to nanoparticle agglomeration. Nanoparticles have high surface energy due to the high specific surface area, and tend to stick together and agglomerate.

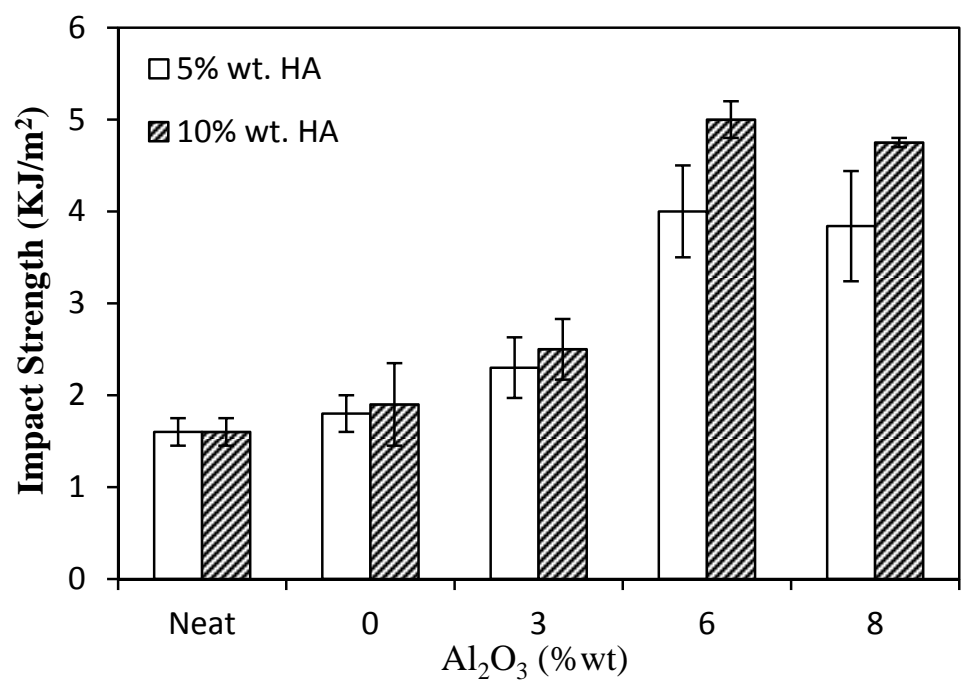

Fig. 5. The effect of adding hydroxyapatite and alumina on the impact strength of blends

Fig. 6 shows the effect of adding hydroxyapatite and alumina nanoparticles on the Vickers hardness number of blends. The hardness of blends was increased significantly with increasing \%wt. of both nanoparticles. Vickers hardness number of hybrid Nano-composite with $10 \% w t$. HA and $8 \%$ wt. of $\mathrm{Al}_{2} \mathrm{O}_{3}$ increased about 2 times than the neat PMMA. This increase in hardness may have been due to inherent characteristics of the $\mathrm{Al}_{2} \mathrm{O}_{3}$ on $\mathrm{HA}$ ceramic Nano-particles. $\mathrm{Al}_{2} \mathrm{O}_{3}$ possesses strong ionic interatomic bonding, giving rise to its desirable material characteristics, such as hardness and strength. The most stable hexagonal alpha phase $\mathrm{Al}_{2} \mathrm{O}_{3}$ is the strongest and stiffest of the oxide ceramics. In addition, HA bio-ceramic nanoparticles have high hardness. Therefore, it is expected that when $\mathrm{HA}$ and $\mathrm{Al}_{2} \mathrm{O}_{3}$ nanoparticles disperse in a matrix, they increase its hardness and strength. Its high hardness, excellent dielectric properties, refractoriness, and good thermal properties make $\mathrm{Al}_{2} \mathrm{O}_{3}$ nanoparticles the material of choice for a wide range of applications (Ellakwa et al., 2008). Furthermore, the white color of ceramic Nano fillers is not expected to affect adversely the aesthetic appearance of denture base resins. 


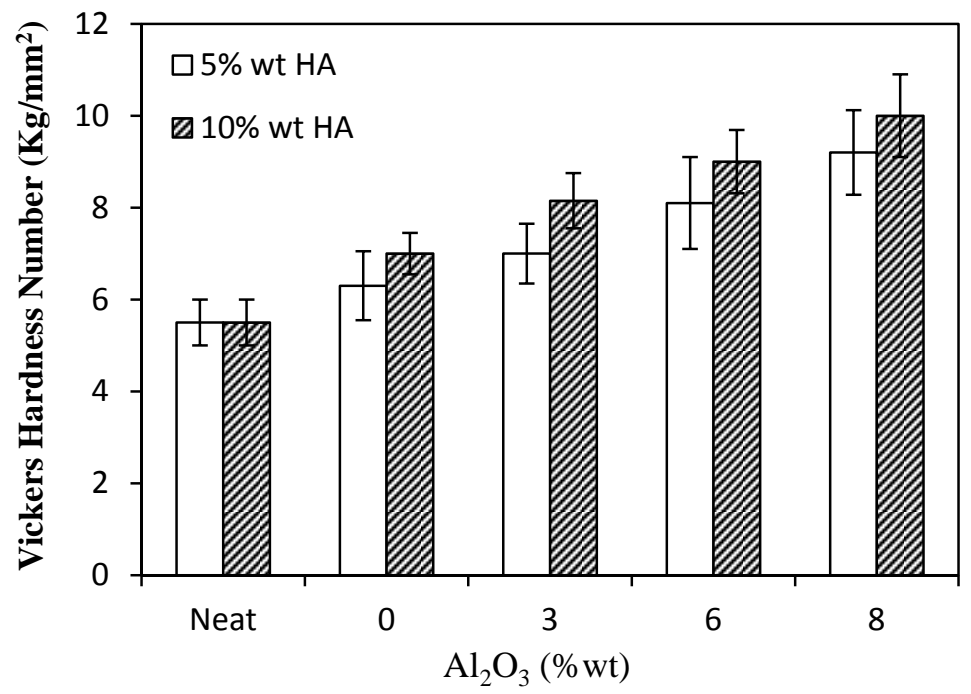

Fig. 6. The effect of adding hydroxyapatite and alumina on the Vickers hardness number of blends

Fig. 7 indicates the effect of nanoparticles on the longitudinal shrinkage of blends. By adding the weight percent of nanoparticles, the shrinkage rate was reduced. This reduction is about $48 \%$ in hybrid Nano-composite with $10 \% w t$. HA and 8 \%wt. $\mathrm{Al}_{2} \mathrm{O}_{3}$ compared to the neat PMMA. The presence of nanoparticles (HA and $\mathrm{Al}_{2} \mathrm{O}_{3}$ ) in the polymer matrix has filling effect. Due to the difference in shrinkage rate of nanoparticles and polymer matrix, the filling effect of nanoparticles maybe to overcome on nucleation effect and the enhancement of nanoparticles may lead to reduce the shrinkage of blends.

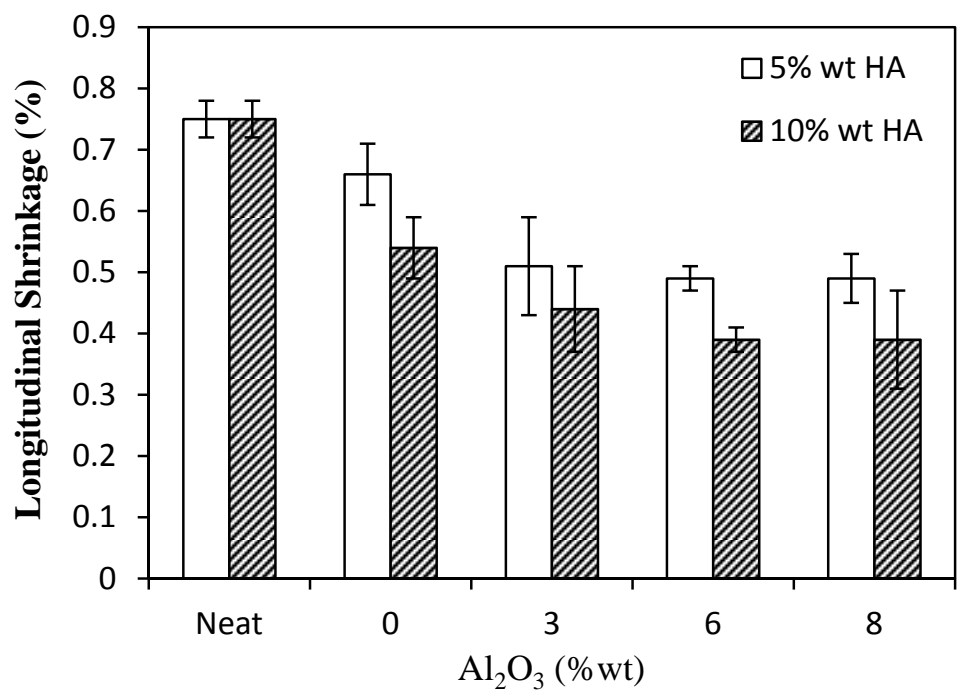

Fig. 7. The effect of adding hydroxyapatite and alumina on the longitudinal shrinkage of blends

\section{Conclusion}

In this study, the influences of Nano-hydroxyapatite and Nano- $\mathrm{Al}_{2} \mathrm{O}_{3}$ on the mechanical properties and shrinkage behavior of $\mathrm{PMMA} / \mathrm{HA} / \mathrm{Al}_{2} \mathrm{O}_{3}$ hybrid Nano-composites were investigated experimentally. 
By adding the weight percentage of hydroxyapatite and alumina nanoparticles flexural strength was increased about 35\% compared to pure PMMA. The impact strength also increased approximately 2.5 times than of neat PMMA. Void formation around nanoparticles led to increase of impact strength. Decrease of impact strength at high percentage of nanoparticles (10\%wt. HA and $\left.8 \% w t . \mathrm{Al}_{2} \mathrm{O}_{3}\right)$ was attributed to the nanoparticle agglomeration. Vickers hardness number of hybrid Nano-composite with $10 \%$ wt. HA and $8 \%$ wt. of $\mathrm{Al}_{2} \mathrm{O}_{3}$ increased about 2 times than the neat PMMA. This increase in hardness may be due to inherent characteristics of the $\mathrm{Al}_{2} \mathrm{O}_{3}$ and high hardness HA nanoparticles. By adding the weight percent of nanoparticles, the longitudinal shrinkage was reduced. This reduction is about $48 \%$ in hybrid Nano-composite with $10 \%$ wt. HA and $8 \% w t$. $\mathrm{Al}_{2} \mathrm{O}_{3}$ compared to the neat PMMA. The blends with $5 \% w t$. HA and $6 \% w t . \mathrm{Al}_{2} \mathrm{O}_{3}$ had the best balance of flexural strength and impact strength and this feature is very important in denture base material.

\section{Acknowledgement}

The authors would like to thank the anonymous referees for constructive comments on earlier version of this paper.

\section{References}

Abdel-Samad, A., \& EL-Fallal, A. (2009). Evaluation of the effect of zirconium oxide on wear resistance and hardness of acrylic teeth. Egypt Dental Association, 55, 639-643.

Ayad, N. M., Badawi, M. F., \& Fatah, A. A. (2008). Effect of reinforcement of high-impact acrylic resin with zirconia on some physical and mechanical properties. Rev. clín. pesq. odontol.(Impr.), 4(3), 145-151.

CallisterJr, W. D. (1997). Materials Science and Engineering: An Introduction, 4; Callister, Jr., William D. Materials Science and Engineering: An Introduction, 4th Edition., New York: John Wiley \& Sons, Inc., copyright, 499-501.

Carroll, C. E., \& Von Fraunhofer, J. A. (1984). Wire reinforcement of acrylic resin prostheses. The Journal of Prosthetic Dentistry, 52(5), 639-641.

Chen, S. Y., Liang, W. M., \& Yen, P. S. (2001). Reinforcement of acrylic denture base resin by incorporation of various fibers. Journal of Biomedical Materials Research, 58(2), 203-208.

Ellakwa, A. E., Morsy, M. A., \& El-Sheikh, A. M. (2008). Effect of Aluminum Oxide Addition on the Flexural Strength and Thermal Diffusivity of Heat-Polymerized Acrylic Resin. Journal of Prosthodontics, 17(6), 439-444.

Dabbar, U.R., \& Huggett, R.H. (1994). A denture fracture-survey. British Dental Journal, 176, 342345.

Furman, B., Rawls, H. R., Wellinghoff, S., Dixon, H., Lankford, J., \&Nicolella, D. (2000). Metaloxide nanoparticles for the reinforcement of dental restorative resins. Critical Reviews ${ }^{\mathrm{TM}}$ in Biomedical Engineering, 28(3\&4).

Grant, A. A., \& Greener, E. H. (1967). Whisker reinforcement of polymethyl methacrylate denture base resins. Australian Dental Journal, 12(1), 29-33.

Gutteridge, D. L. (1988). The effect of including ultra-high-modulus polyethylene fibre on the impact strength of acrylic resin. British Dental Journal, 164(6), 177.

Hargreaves, A. S. (1969). The prevalence of fractured dentures. A survey. British dental journal, 126(10), 451.

Ichikawa, Y., Akagawa, Y., Nikai, H., \&Tsuru, H. (1992). Tissue compatibility and stability of a new zirconia ceramic in vivo. The Journal of Prosthetic Dentistry, 68(2), 322-326.

Jagger, D. C., Harrison, A., \& Jandt, K. D. (1999). The reinforcement of dentures. Journal of Oral Rehabilitation, 26(3), 185-194.

Johnston, E. P., Nicholls, J. I., \& Smith, D. E. (1981). Flexure fatigue of 10 commonly used denture base resins. The Journal of prosthetic dentistry, 46(5), 478-483. 
Kim, S. H., \& Watts, D. C. (2004). The effect of reinforcement with woven E-glass fibers on the impact strength of complete dentures fabricated with high-impact acrylic resin. The Journal of Prosthetic Dentistry, 91(3), 274-280.

Lambrecht, J. R., \&Kydd, W. L. (1962). A functional stress analysis of the maxillary complete denture base. The Journal of Prosthetic Dentistry, 12(5), 865-872.

Matsukawa, S., Hayakawa, T., \&Nemoto, K. (1994). Development of high-toughness resin for dental applications. Dental Materials, 10(6), 343-346.

McNally, L., O'sullivan, D. J., \& Jagger, D. C. (2006). An in vitro investigation of the effect of the addition of untreated and surface treated silica on the transverse and impact strength of poly (methyl methacrylate) acrylic resin. Bio-medical Materials and Engineering, 16(2), 93-100.

Minamizato, T. (1990). Slip-cast zirconia dental roots with tunnels drilled by laser process resin. The Journal of Prosthetic Dentistry, 63, 677-684.

Panyayong, W., Oshida, Y., Andres, C. J., Barco, T. M., Brown, D. T., \&Hovijitra, S. (2002). Reinforcement of acrylic resins for provisional fixed restorations. Part III: effects of addition of titania and zirconia mixtures on some mechanical and physical properties. Bio-Medical Materials and Engineering, 12(4), 353-366.

Powers, J. M., \& Sakaguchi, R. L. (2006). Craig's Restorative Dental Materials, 13/e. Elsevier India.

Radford, D. R., Sweet, S. P., Challacombe, S. J., \& Walter, J. D. (1998). Adherence of Candida albicansto denture-base materials with different surface finishes. Journal of dentistry, 26(7), 577583.

Robinson, M.J. (1993). Impact strength of acrylic resin denture base materials with surface detects. Dental Materials, 9, 355-360.

Ruffino, A. R. (1985). Effect of steel strengtheners on fracture resistance of the acrylic resin complete denture base. The Journal of Prosthetic Dentistry, 54(1), 75-78.

Saad-Eldeen, M. A., AL-Fallal, A. A., \&Abouelatta, O. B. (2007). Effect of zirconium oxide reinforcement on epithelial oral mucosa, Immunoglobulin and surface roughness of complete acrylic heat-cured denture. Egypt Dent Associat, 53, 941-946.

Sehajpal, S. B., \&Sood, V. K. (1989). Effect of metal fillers on some physical properties of acrylic resin. The Journal of Prosthetic Dentistry, 61(6), 746-751.

Shibata, T., Hamada, N., Kimoto, K., Sawada, T., Sawada, T., Kumada, H., ...\& Toyoda, M. (2007). Antifungal effect of acrylic resin containing apatite-coated TiO2 photocatalyst. Dental Materials Journal, 26(3), 437-444.

Sodagar, A., Kassaee, M. Z., Akhavan, A., Javadi, N., Arab, S., \&Kharazifard, M. J. (2012). Effect of silver nano particles on flexural strength of acrylic resins. Journal of prosthodontic research, 56(2), 120-124.

Stafford, G. D., Bates, J. F., Huggett, R., \& Handley, R. W. (1980). A review of the properties of some denture base polymers. Journal of dentistry, 8(4), 292-306.

Sun, L., Gibson, R. F., Gordaninejad, F., \&Suhr, J. (2009). Energy absorption capability of nanocomposites: a review. Composites Science and Technology, 69(14), 2392-2409.

Tinschert, J., Natt, G., Mautsch, W., Augthun, M., \&Spiekermann, H. (2001). Fracture Resistance of Lithium Disilicate--, Alumina-, and Zirconia-Based Three-Unit Fixed Partial Dentures: A Laboratory Study. International Journal of Prosthodontics, 14(3).

Uzun, G., Hersek, N., \&Tincer, T. (1999). Effect of five woven fiber reinforcements on the impact and transverse strength of a denture base resin. The Journal of prosthetic dentistry, 81(5), 616-620.

Vallittu, P. K., \&Lassila, V. P. (1992). Effect of metal strengthener's surface roughness on fracture resistance of acrylic denture base material. Journal of oral rehabilitation, 19(4), 385-391.

Vallittu, P. K. (1993). Effe1ct of some properties of metal strengtheners on the fracture resistance of acrylic denture base material construction. Journal of oral rehabilitation, 20(3), 241-248.

Verran, J., \&Maryan, C. J. (1997). Retention of Candida albicans on acrylic resin and silicone of different surface topography. The Journal of prosthetic dentistry, 77(5), 535-539. 
Zarb, G. A., Bolender, C. L., Eckert, S. E., Jacob, R., Fenton, A., \&Mericske-Stern, R. (2004). Prosthodontic treatment for edentulous patients. Complete dentures and implant-supported prostheses. 12th. ed. St. Louis: Mosby.

Zuccari, A. G., Oshida, Y., \& Moore, B. K. (1997). Reinforcement of acrylic resins for provisional fixed restorationsPart I: Mechanical properties. Bio-medical materials and engineering, 7(5), 327343. 